\title{
Statins Use in Diabetes Patients as Primary Prevention and Low-Density Lipoprotein Cholesterol Levels
}

\author{
Chuyun Sun \\ Miss Hall's School, Pittsfield, MA, USA \\ 492 Holmes rd \\ Pittsfield, MA, USA \\ 14132128557 \\ Csun@misshalls.org
}

\begin{abstract}
Few data are available on the use of statins among the type 2 diabetes patients for primary prevention after publication of the American Diabetes Association guidelines in 2008. The American Diabetes Association (ADA) standards of care for diabetes state that statin therapy should be initiated in individuals with diabetes and other cardiovascular risk factors with a target LDL cholesterol of $100 \mathrm{mg} / \mathrm{dl}$. This paper is to determine statin use in diabetes patients as primary prevention and its impact on low-density lipoprotein cholesterol (LDL-C) control among US individuals in year 2011-2012.

In the research, diabetes patients were first identified among participants of the National Health and Nutrition Examination Survey (NHANES) 2011-2012. Patients were excluded if they had any cardiovascular events including congestive heart failure, heart failure, and stroke before as statin usually recommend for secondary prevention among these patients. Statin use was obtained from review of participants' drug containers. LDL-C control (yes) were defined was defined as $<100 \mathrm{mg} / \mathrm{dl}$. A logistic regression was conducted first to understand the characteristics associated with statin use as primary prevention among diabetes patients. A secondary logistic regression was done to examine the effect of statin on LDL-C control. Finally a linear regression model was used to look at the impact of statin on LDL-C as a continuous variable. Full Sample 2 Year Interview Weight (WTINT2YR) was applied for all the analysis. A total of 598 patients were identified and the weighted sample size was $17,387,156$ for the data analysis.
\end{abstract}

The conclusion comes out to be that statin use was associated with substantial improvements in LDL-C control in this study. Nevertheless, suboptimal statin use, especially among women and individuals with lower family income, prevented the maximal public health benefit from statin as a primary prevention among diabetes population.

Permission to make digital or hard copies of all or part of this work for personal or classroom use is granted without fee provided that copies are not made or distributed for profit or commercial advantage and that copies bear this notice and the full citation on the first page. To copy otherwise, or republish, to post on servers or to redistribute to lists, requires prior specific permission and/or a fee. Request permissions from Permissions@acm.org.

ICMHI '17, May 20-22, 2017, Taichung City, Taiwan

(C) 2017 Association for Computing Machinery. ACM ISBN 978-1-45035224-6/17/05 ..\$15.00

DOI: http://dx.doi.org/10.1145/3107514.3107520

\section{CCS Concepts}

- Human-centered computing--> Human computer interaction (HCI)-->HCI design and evaluation methods-->User models.

\section{Keywords}

Logistic Regression; Statins Use; Low-Density Lipoprotein Cholesterol Level; Cardiovascular Disease; Type 2 Diabetes.

\section{INTRODUCTION}

The prevalence of diabetes for all age-groups worldwide was estimated to be $2.8 \%$ (171 million) in the year 2000, and the projected number could rise to $4.4 \%$ (366 million) in $2030^{[1]}$. This rapid rise is mainly attributable to the increase of diabetes. The continuing escalation of obesity and the metabolic syndrome contribute to the upsurge in frequency of diabetes.

Diabetes is a significant cardiovascular risk factor (conferring a three time absolute adjusted risk of Cardiovascular disease (CVD) death). Furthermore, in individuals with diabetes, a log linear relationship exists between cholesterol levels and CVD regardless of the baseline $\mathrm{LDL}^{[2]}$. Thus, it was assumed, that regardless of the baseline cholesterol level, reducing the LDL will reduce the occurrence of CVD. CVD is one of the foremost causes of mortality and is a major contributor to morbidity for individuals with diabetes. In addition, diabetes is an independent risk factor for macrovascular disease, as are the common coexisting conditions (hypertension and dyslipidemia). The U.K. Prospective Diabetes Study (UKPDS) evaluated baseline risk factors for coronary artery disease in patients with newly diagnosed diabetes without evidence of vascular disease ${ }^{[3]}$. When comparing the relative contribution of the three modifiable coexisting conditions (dyslipidemia, hypertension, and hyperglycemia) with development of future coronary heart disease (CHD), the estimated hazard ratio (HR) for the upper third, relative to the lower third, for LDL cholesterol, systolic blood pressure, and A1C were $2.26,1.82$, and 1.52 , respectively ${ }^{[4]}$. This finding supports the notion that dyslipidemia, and specifically LDL cholesterol, are major contributors to the increased CHD risk in patients with diabetes.

The American Diabetes Association (ADA) standards of care for diabetes state that statin therapy should be initiated in individuals with diabetes and other cardiovascular risk factors with a target LDL cholesterol of $100 \mathrm{mg} / \mathrm{dl}$. Few data are available on the use of statins among the type 2 diabetes patients for primary prevention after publication of the American Diabetes Association guidelines in 2008. This study aimed to determine statin use in diabetes patients as primary prevention and its impact on low- 
density lipoprotein cholesterol (LDL-C) control among US individuals in year 2011-2012.

\section{DATA AND METHODS}

\subsection{Data}

NHANES is a series of stratified, multistage probability surveys designed to obtain information on the health and nutritional status of the civilian, US population. From 1999, NHANES data have been collected continuously, with every 2 years serving as 1 analytical cycle. The data are collected by the National Center for Health Statistics, CDC, via household interviews and physical examinations and are intended to provide estimates that are representative of the US population. Detailed information is available elsewhere. (http://www.cdc.gov/nchs/nhanes.htm)

Diabetes patients were first identified among participants of the National Health and Nutrition Examination Survey (NHANES) 2011-2012. Patients were excluded if they had any cardiovascular events including congestive heart failure, heart failure, and stroke before as statin usually recommend for secondary prevention among these patients. Statin use was obtained from review of participants' drug containers. LDL-C control (yes) were defined was defined as $<100 \mathrm{mg} / \mathrm{dl}$. A logistic regression was conducted first to understand the characteristics associated with statin use as primary prevention among diabetes patients. A secondary logistic regression was done to examine the effect of statin on LDL-C control. Finally a linear regression model was used to look at the impact of statin on LDL-C as a continuous variable. Full Sample 2 Year Interview Weight (WTINT2YR) was applied for all the analysis.

\subsection{Inclusion and exclusions criteria}

Participants in NHANES will be included in the study if the following inclusion criteria are met:

1) Positive diabetes diagnosis

2) Valid statin use status (yes or no)

Participants in NHANES will be excluded in the study if the following inclusion criteria are met:

1) Had CVD event before including congestive heart failure, heart failure, and stroke before as statin usually recommend for secondary prevention among these patients

\subsection{Variables}

Below are the list of variables which are available in the big data. It is quite comprehensive compared to other public data as it has statins use and LDL-C lab results which makes our research possible.

Age: two groups were built: $>=75$ or $<75$

Gender: male, female

Race: Hispanic, Non-hispanic whites, Non-hispanic blacks, Nonhispanic Asia, others

Marital status: married or not

Education level: This variable is the highest grade or level of education completed by adults 20 years and older. The response categories are: less than 9th grade education, 9-11th grade education (includes 12th grade and no diploma), High school graduate/GED, some college or associates (AA) degree, and college graduate or higher.
Income level: This variable is the ratio of family income to poverty. The Department of Health and Human Services (HHS) poverty guidelines were used as the poverty measure to calculate this ratio. These guidelines are issued each year, in the Federal Register, for determining financial eligibility for certain federal programs, such as Head Start, Supplemental Nutrition Assistance Program (SNAP), Special Supplemental Nutrition Program for Women, Infants, and Children (WIC), and the National School Lunch Program. The poverty guidelines vary by family size and geographic location.

Hypertension: higher blood pressure $>=2$ times

Statins use: yes or no

LDL-C: Serum LDL-cholesterol levels were derived on examinees that were examined in the morning session only. The distribution of serum LDL-cholesterol should be estimated only on examinees aged 12 and above who fasted at least 8.5 hours or more but less than 24 hours in the morning session. LDLcholesterol is calculated from measured values of total cholesterol, triglycerides, and HDL-cholesterol according to the Friedewald calculation:

$[$ LDL-cholesterol $]=[$ total cholesterol $]-[$ HDL-cholesterol $]-$ [triglycerides/5]

where all values are expressed in $\mathrm{mg} / \mathrm{dL}$. The calculation is valid for triglycerides less than or equal to $400 \mathrm{mg} / \mathrm{dL}$.

\section{RESULTS}

A total of 598 patients were identified and the weighted sample size was $17,387,156$ for the data analysis. About $45 \%$ diabetes patients without CVD event history were currently using statin for primary prevention.

Table 1. Patients characteristics

\begin{tabular}{|c|c|c|}
\hline & \multicolumn{2}{|c|}{ Statin Use } \\
\hline & No & Yes \\
\hline & $\%$ & $\%$ \\
\hline \multicolumn{3}{|c|}{ Sex } \\
\hline Male & 45.93 & 56.72 \\
\hline Female & 54.07 & 43.28 \\
\hline \multicolumn{3}{|c|}{ Age } \\
\hline Age $<75$ & 88.53 & 82.97 \\
\hline Age $>=75$ & 11.47 & 17.03 \\
\hline \multicolumn{3}{|c|}{ Race } \\
\hline Asia & 4.62 & 5.86 \\
\hline Black & 17.47 & 17.77 \\
\hline Other & 23.41 & 14.06 \\
\hline White & 54.5 & 62.31 \\
\hline \multicolumn{3}{|c|}{ Marital status } \\
\hline Not Married & 51.64 & 38.48 \\
\hline
\end{tabular}




\begin{tabular}{|c|c|c|}
\hline Married & 48.36 & 61.52 \\
\hline \multicolumn{3}{|l|}{ Education } \\
\hline Less than 9th grade & 14.71 & 9.4 \\
\hline 9-11th grade & 11.89 & 14.07 \\
\hline High school graduate/GED or equivalent & 28.11 & 23.64 \\
\hline Some college or AA degree & 21.4 & 30.2 \\
\hline College graduate or above & 23.88 & 22.68 \\
\hline \multicolumn{3}{|c|}{ Ratio of family income to poverty } \\
\hline$<1$ & 24.86 & 17.32 \\
\hline$<2$ & 30.01 & 20.57 \\
\hline$<3$ & 16.9 & 16.05 \\
\hline$<4$ & 7.28 & 13.74 \\
\hline$<5$ & 10.79 & 12.77 \\
\hline 5 & 10.16 & 19.55 \\
\hline \multicolumn{3}{|l|}{ Hypertension } \\
\hline No & 46.87 & 36.47 \\
\hline Yes & 53.13 & 63.53 \\
\hline \multicolumn{3}{|l|}{ Current Smoker } \\
\hline No & 85.65 & 84.84 \\
\hline Yes & 14.35 & 15.16 \\
\hline
\end{tabular}

The female were less likely to be on statin than the male (odds ratio (OR): 0.785 , 95\% Confidence Interval (CI): 0.783-0.787). Patients who were aged 75 or older were more likely to receive statin compared less than 75 years old $(\mathrm{OR}=1.709$, 95\% CI: 1.704-1.714). Higher Ratio of family income to poverty was significantly associated with higher probability to receive statin $(\mathrm{p}<0.001)$. Other characteristics, including race, marital status, education level, hypertension status and smocking status were all significantly associated with statin use.

Table 2. Logistic regression on statin use

\begin{tabular}{|c|c|c|c|}
\hline Effect & $\begin{array}{c}\text { Point } \\
\text { Estimate }\end{array}$ & \multicolumn{2}{|c|}{$\begin{array}{c}\text { 95\% Wald } \\
\text { Confidence Limits }\end{array}$} \\
\hline Female & 0.785 & 0.783 & 0.787 \\
\hline Age>=75 & 1.709 & 1.704 & 1.714 \\
\hline \multicolumn{4}{|c|}{ Race (reference=white) } \\
\hline Asia & 1.259 & 1.253 & 1.266 \\
\hline Black & 1.018 & 1.015 & 1.021 \\
\hline Other & 0.678 & 0.676 & 0.68 \\
\hline
\end{tabular}

\begin{tabular}{|c|c|c|c|}
\hline Married, yes & 1.4 & 1.397 & 1.403 \\
\hline \multicolumn{2}{|c|}{ Education level (reference=Less than 9th grade) } \\
\hline 9-11th grade & 1.532 & 1.525 & 1.539 \\
\hline $\begin{array}{c}\text { High school } \\
\text { graduate/GED or } \\
\text { equivalent }\end{array}$ & 0.93 & 0.926 & 0.934 \\
\hline $\begin{array}{c}\text { Some college or } \\
\text { AA degree }\end{array}$ & 1.694 & 1.687 & 1.701 \\
\hline $\begin{array}{c}\text { College graduate } \\
\text { or above }\end{array}$ & 0.674 & 0.671 & 0.677 \\
\hline Ratio of family income to poverty (reference level= <1) \\
\hline$<\mathbf{2}$ & 0.908 & 0.905 & 0.911 \\
\hline$<\mathbf{3}$ & 1.348 & 1.343 & 1.353 \\
\hline$<\mathbf{4}$ & 2.745 & 2.733 & 2.757 \\
\hline$<\mathbf{5}$ & 1.708 & 1.701 & 1.715 \\
\hline $\mathbf{5}$ & 2.776 & 2.764 & 2.788 \\
\hline Hypertension, yes & 1.323 & 1.32 & 1.326 \\
\hline Smoking, yes & 1.382 & 1.378 & 1.386 \\
\hline
\end{tabular}

A total of $8453892(48.6 \%)$ patients had LDL-C results. The average LDL-C among statin users was 83.0 and it was 114.0 among non-statin users. The LDL-C control rate was $73.1 \%$ among statin users versus $36.0 \%$ among non-statin users.

Table 3. LDL-C descriptive information among statin users and non-statin users

\begin{tabular}{|l|l|l|l|l|l|l|l|}
\hline $\begin{array}{l}\text { stati } \\
\mathbf{n}\end{array}$ & $\mathbf{N}$ & Mean & $\begin{array}{l}\text { Std D } \\
\text { ev }\end{array}$ & $\begin{array}{l}\text { Std E } \\
\text { rr }\end{array}$ & $\begin{array}{l}\text { Minim } \\
\text { um }\end{array}$ & $\begin{array}{l}\text { Medi } \\
\text { an }\end{array}$ & $\begin{array}{l}\text { Maxim } \\
\text { um }\end{array}$ \\
\hline No & $\begin{array}{l}14 \\
2\end{array}$ & 114 & 6287 & $\begin{array}{l}2.947 \\
7\end{array}$ & 24 & 111 & 290 \\
\hline Yes & $\begin{array}{l}12 \\
8\end{array}$ & $\begin{array}{l}83.03 \\
32\end{array}$ & $\begin{array}{l}5343 \\
8\end{array}$ & $\begin{array}{l}2.704 \\
3\end{array}$ & 15 & 74 & 182 \\
\hline
\end{tabular}

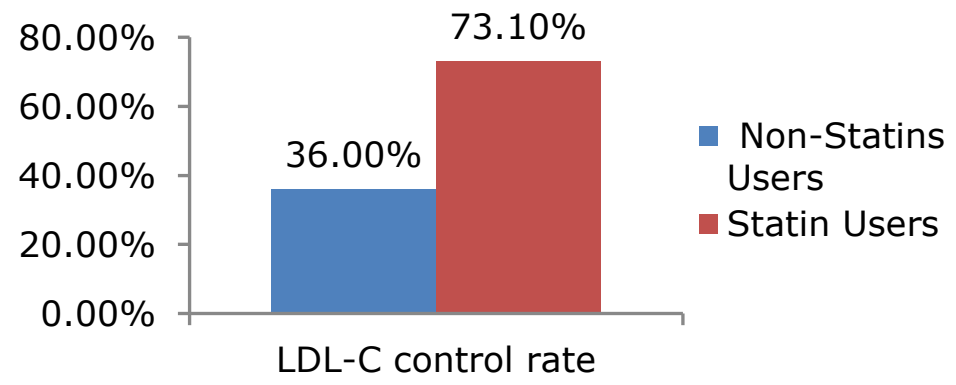

Figure 1. LDL-C control rate $(<100 \mathrm{mg} / \mathrm{dl})$ among statin users and non-statin users 


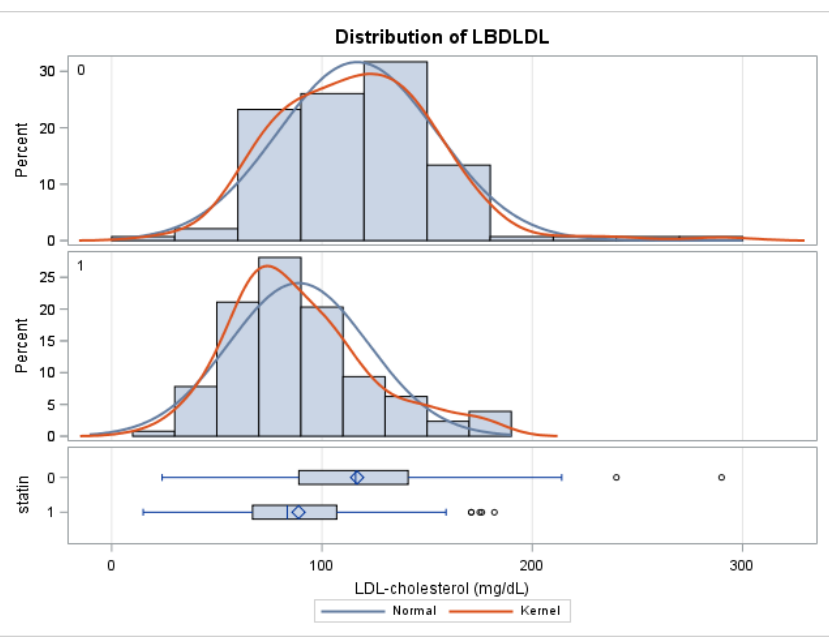

Figure 2.Distribution of LDL-C among non-statin users and statin users

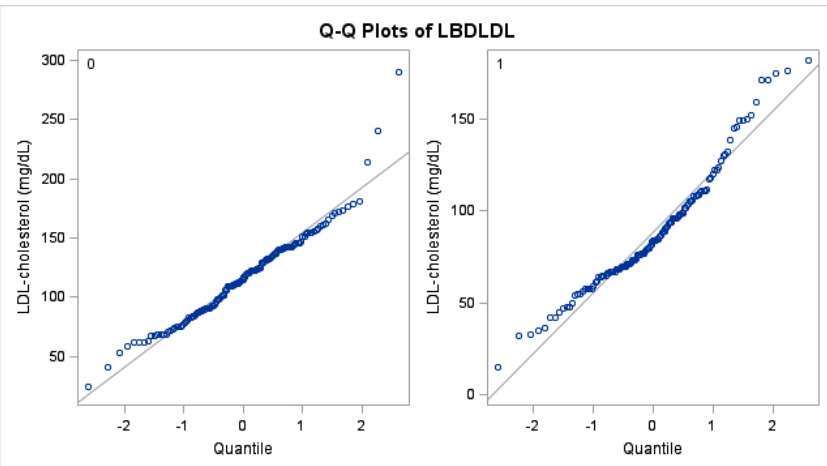

Figure 3. Q-Q plot of LDL-C non-statin users (Left) and statin users (Right)

After controlling after these characteristics, statin use was associated with a reduction of LDL-C by $28 \mathrm{mg} / \mathrm{dl}$ (95\% CI: $19-$ $37)$ and a 4.614 (95\% CI: 4.597 -4.631) higher likelihood to have a LDL-C $<100 \mathrm{mg} / \mathrm{dl}$ according to a multivariate linear regression and a multivariate logistic regression, respectively.

Table 4. Linear regression on LDL-C among non-statin users and statin users

\begin{tabular}{|c|c|c|c|c|c|c|}
\hline Parameter & & $\begin{array}{c}\text { Estima } \\
\text { te }\end{array}$ & $\begin{array}{c}\text { Standar } \\
\mathbf{d} \\
\text { Error }\end{array}$ & \multicolumn{2}{|c|}{$\begin{array}{c}\text { Wald } \\
\text { 95\% } \\
\text { Confiden } \\
\text { ce Limits }\end{array}$} & $\begin{array}{c}\text { Pr > Chi } \\
\text { Sq }\end{array}$ \\
\hline Intercept & & 117 & 10 & 98 & 136 & $<.0001$ \\
\hline Statin (yes) & 1 & -28 & 5 & -37 & -19 & $<.0001$ \\
\hline Female & 1 & 5 & 4 & -4 & 13 & 0.263 \\
\hline Age>=75 & 1 & -1 & 6 & -13 & 11 & 0.865 \\
\hline \multicolumn{1}{|c|}{ Asia } & Asia & 1 & 11 & -20 & 23 & 0.898 \\
\hline Black & $\begin{array}{c}\text { Blac } \\
\mathrm{k}\end{array}$ & 10 & 6 & -2 & 23 & 0.095 \\
\hline Other & $\begin{array}{c}\text { Othe } \\
\mathrm{r}\end{array}$ & 15 & 6 & 3 & 27 & 0.019 \\
\hline $\begin{array}{c}\text { Married, } \\
\text { yes }\end{array}$ & \begin{tabular}{c}
1 \\
\hline
\end{tabular} & -1 & 5 & -10 & 8 & 0.778 \\
\hline
\end{tabular}

Education level (reference=Less than 9th grade)

\begin{tabular}{|c|c|c|c|c|c|c|}
\hline $\begin{array}{c}\text { 9-11th } \\
\text { grade }\end{array}$ & 2 & -6 & 9 & -23 & 12 & 0.527 \\
\hline $\begin{array}{c}\text { High school } \\
\text { graduate/G } \\
\text { ED or } \\
\text { equivalent }\end{array}$ & 3 & 7 & 9 & -10 & 25 & 0.417 \\
\hline $\begin{array}{c}\text { Some } \\
\text { college or } \\
\text { AA degree }\end{array}$ & 4 & -8 & 8 & -24 & 9 & 0.348 \\
\hline $\begin{array}{c}\text { College } \\
\text { graduate or } \\
\text { above }\end{array}$ & 5 & -3 & 9 & -20 & 15 & 0.751 \\
\hline
\end{tabular}

Ratio of family income to poverty (reference level= <1)

\begin{tabular}{|c|c|c|c|c|c|c|}
\hline$<\mathbf{2}$ & 1 & -8 & 7 & -22 & 5 & 0.208 \\
\hline$<\mathbf{3}$ & 2 & -8 & 8 & -24 & 7 & 0.294 \\
\hline$<\mathbf{4}$ & 3 & -7 & 9 & -25 & 10 & 0.414 \\
\hline$<\mathbf{5}$ & 4 & -14 & 8 & -30 & 3 & 0.103 \\
\hline $\mathbf{5}$ & 5 & -2 & 9 & -20 & 16 & 0.825 \\
\hline $\begin{array}{c}\text { Hypertensio } \\
\text { n, yes }\end{array}$ & 1 & -2 & 4 & -10 & 7 & 0.716 \\
\hline $\begin{array}{c}\text { Smoking, } \\
\text { yes }\end{array}$ & 1 & -10 & 6 & -22 & 2 & 0.112 \\
\hline
\end{tabular}


Table 5. Logistic regression on LDL-C control (<100 mg/dl) among non-statin users and statin users

\begin{tabular}{|c|c|c|c|}
\hline Effect & Point Estimate & \multicolumn{2}{|c|}{$\begin{array}{c}95 \% \text { Wald } \\
\text { Confidence Limits }\end{array}$} \\
\hline Statin (yes) & 4.614 & 4.597 & 4.631 \\
\hline Female & 0.872 & 0.869 & 0.875 \\
\hline Age $>=75$ & 1.003 & 0.998 & 1.008 \\
\hline \multicolumn{4}{|c|}{ Race $($ reference $=$ white $)$} \\
\hline Asia & 0.866 & 0.859 & 0.874 \\
\hline Black & 0.708 & 0.705 & 0.712 \\
\hline Other & 0.405 & 0.403 & 0.408 \\
\hline Married, yes & 1.061 & 1.057 & 1.065 \\
\hline \multicolumn{4}{|c|}{ Education level (reference=Less than 9th grade) } \\
\hline 9-11th grade & 0.51 & 0.506 & 0.513 \\
\hline High school graduate/GED or equivalent & 0.242 & 0.24 & 0.244 \\
\hline Some college or AA degree & 0.815 & 0.809 & 0.821 \\
\hline College graduate or above & 0.46 & 0.457 & 0.464 \\
\hline \multicolumn{4}{|c|}{ Ratio of family income to poverty (reference level= $<1$ ) } \\
\hline$<2$ & 3.331 & 3.313 & 3.349 \\
\hline$<3$ & 2.974 & 2.955 & 2.994 \\
\hline$<4$ & 2.316 & 2.3 & 2.332 \\
\hline$<5$ & 3.386 & 3.363 & 3.409 \\
\hline 5 & 1.258 & 1.249 & 1.267 \\
\hline Hypertension, yes & 1.066 & 1.063 & 1.07 \\
\hline Smoking, yes & 1.749 & 1.74 & 1.758 \\
\hline
\end{tabular}

\section{DISCUSSION}

Few data are available on the use of statins among the type 2 diabetes patients for primary prevention after publication of the American Diabetes Association guidelines in 2008. The American Diabetes Association (ADA) standards of care for diabetes state that statin therapy should be initiated in individuals with diabetes and other cardiovascular risk factors with a target LDL cholesterol of $100 \mathrm{mg} / \mathrm{dl}$. This led to a number of primary cardiovascular prevention trials using statin therapy as the principal intervention. It has been clearly shown (and thus clearly incorporated into the ADA guidelines) that diabetic individuals with other risk factors should indeed be treated with a statin. ${ }^{[5,6]}$

In this study, less than $50 \%$ diabetes patients without CVD event history were currently using statin for primary prevention. The female were less likely to be on statin than the male (odds ratio
(OR): 0.785 , 95\% Confidence Interval (CI): 0.783-0.787) Patients who were aged 75 or older were more likely to receive statin compared less than 75 years old $(\mathrm{OR}=1.709$, 95\% CI: 1.704-1.714). Higher Ratio of family income to poverty was significantly associated with higher probability to receive statin ( $\mathrm{p}<0.001)$. Other characteristics, including race, marital status, education level, hypertension status and smocking status were all significantly associated with statin use.

The LDL-C control rate was $73.1 \%$ among statin users versus $36.0 \%$ among non-statin users. After controlling after these characteristics, statin use was associated with a reduction of LDL-C by $28 \mathrm{mg} / \mathrm{dl}$ and almost 5 times higher likelihood to have a LDL-C $<100 \mathrm{mg} / \mathrm{dl}$. The American Diabetes Association (ADA) standards of care for diabetes state that statin therapy should be initiated in individuals with diabetes and other cardiovascular risk factors with a target LDL cholesterol of $<100 \mathrm{mg} / \mathrm{dl}$. Statin therapy should be added to lifestyle therapy, 
regardless of baseline lipid levels, for diabetic patients a) with overt cardiovascular disease (CVD) (A: level of evidence as described in the ADA evidence-grading system; the primary goal is an LDL cholesterol $<100 \mathrm{mg} / \mathrm{dl}(<2.6 \mathrm{mmol} / \mathrm{l})$ (A); a lower LDL cholesterol goal of $70 \mathrm{mg} / \mathrm{dl}(1.8 \mathrm{mmol} / \mathrm{l})$, using a high dose of a statin, is an option (E); and b) without CVD who are over the age of 40 years and have one or more other CVD risk factor. The primary goal is an LDL cholesterol $<100 \mathrm{mg} / \mathrm{dl}$ $(<2.6 \mathrm{mmol} / \mathrm{l})(\mathrm{A})$.

There are limitations in this study. We did not have LDL-C lab results for everyone included in this analysis and missing could be not random in which case our estimate would be biased. We did not examine other drug use to lower LDL-C except statin. Some benefits we saw among statin users could be attributed additional therapy. However statin is the first line therapy therefore first choice therapy for patients who have cardiovascular risk concerns. For a patient who was not on statin, the probability for him or her to receive other lipid lowering therarpy were very remote. We did not examine the statin effect on CVD instance rate. But the relation between LDL-C and CVD risk is clearly established in the literature and this study clearly shown the capability of statin to significantly lower the LDL-C in diabetes population without CVD event history.

In this study we found that statin use was associated with substantial improvements in LDL-C control in this study. An absolute reduction of $28 \mathrm{mg} / \mathrm{dl}$ of LDL-C and a 5 times higher rate of controlled rate were reported in this study. This is nothing trivial for a population with elevated risk for cardiovascular events. Nevertheless, suboptimal statin use, especially among women and individuals with lower family income, prevented the maximal public health benefit from statin as a primary prevention among diabetes population. Lower use of statin among poor population is a society issue as they would be more likely to use public healthcare resource for example Medicaid to cover the downstream CVD events. More attention should be paid to this issue and public health policy maker should consider introducing statin coverage no matter what their insurance coverage status.

\section{REFERENCES}

[1] Wild S, Roglic G, Green A, Sicree R, King H.2004. Global prevalence of diabetes: estimates for the year 2000 and projections for 2030. Diabetes Care. May, 2004; 27(5):1047-53.

[2] Roy Eldor and Itamar Raz. 2009. American Diabetes Association Indications for Statins in Diabetes: Is there evidence? Diabetes Care. Nov, 2009; 32(Suppl 2): S384S391.

[3] Turner RC1, Millns H, Neil HA, Stratton IM, Manley SE, Matthews DR, Holman RR. 1998. Risk factors for coronary artery disease in non-insulin dependent diabetes mellitus: United Kingdom Prospective Diabetes Study (UKPDS: 23). BMJ. Mar 14, 1998;316(7134):823-8.

[4] YEHUDA KAMAR. 2009. Should All Diabetic Patients Be Treated With a Statin? Diabetes Care. Nov, 2009; 32(Suppl 2): S378-S383.

[5] Sever PS, Poulter NR, Dahlof B, Wedel H, Collins R, Beevers G, Caulfield M, Kjeldsen SE, Kristinsson A, McInnes GT, Mehlsen J, Nieminen M, O'Brien E, Ostergren J. 2005. Reduction in cardiovascular events with atorvastatin in 2,532 patients with type 2 diabetes: AngloScandinavian Cardiac Outcomes Trial-lipid-lowering arm (ASCOT-LLA). Diabetes Care 2005; 28: 1151- 1157

[6] Colhoun HM, Betteridge DJ, Durrington PN, Hitman GA, Neil HA, Livingstone SJ, Thomason MJ, Mackness MI, Charlton-Menys V, Fuller JH.2004. Primary prevention of cardiovascular disease with atorvastatin in type 2 diabetes in the Collaborative Atorvastatin Diabetes Study (CARDS): multicentre randomised placebo-controlled trial. Lancet 2004; 364: 685-696 